\title{
Prevailing Status and Treatment Seeking Awareness Among Patients Attending in The Orthodontics Department of Bangabandhu Sheikh Mujib Medical University
}

\author{
Tanzila Rafique ${ }^{1}$, Gazi Shamim Hassan², Md. Nazmul Hasan ${ }^{3}$, Saeed Hossain Khan ${ }^{4}$ \\ ${ }^{1}$ Medical Officer, Dept. of Orthodontics, BSMMU, ${ }^{2}$ Chairman \& Associate Professor, Dept. of Orthodontics, BSMMU, ${ }^{3}$ Assistant \\ Professor, Dept. of Orthodontics \& Dentofacial Orthopedics, Update Dental College, ${ }^{4}$ FCPS Student, Dept. of Orthodontics, BSMMU.
}

\begin{abstract}
:
Background: Malocclusion is problem since antiquity. But people's perception about the problem varies with their geographical location and cultural background. The problem seems to be more acute in developing countries like Bangladesh. Objectives: The present study was undertaken to assess the awareness about aesthetic problem of malocclusion and treatment seeking behavior among the patients attending in orthodontic department of BSMMU. Methods: The present cross-sectional study was carried out in the Department of Orthodontic, Faculty of Dentistry, BSMMU, over a period 24 months from January 2008 to December 2009. A total of 110 participants who were suffering from malocclusion and came for dental treatment were the study population. Results: The mean age of the patients was 21 years and the youngest and the oldest patients were 8 and 32 years old respectively with female to male ratio being roughly 3:2. Graduate or postgraduate level educated patients were predominant (53.6\%). Over $70 \%$ of the respondents viewed malocclusion as an aesthetic problem, $50 \%$ as functional problem, $55.5 \%$ social problem and $69.1 \%$ oral problem. Two-third (67\%) told that malocclusion was a treatable condition. Approximately $43 \%$ of the patients identified trauma as a cause of malocclusion, $40 \%$ gingivitis or periodontitis and $35.5 \%$ dental caries. About one-third (32.7\%) of the respondents was of the opinion that certain habits should be avoided to prevent malocclusion, $15.5 \%$ told timely treatment of malocclusion, $30 \%$ told prevention of early loss of teeth due to caries, $12.7 \%$ were in favour of the use of a space maintainer in places of premature loss of a deciduous tooth. Over $90 \%$ of the respondents held the view that symptoms of malocclusion, its prevention and different treatment options should get the priority in educating the society about malocclusion. However, $80 \%$ of the respondents told that causative factors should discussed. Regarding ways of behaviour change communication (BCC), TV got the first priority (94\%) followed by newspaper (92\%), teacher (88\%), school health programme (84.5\%), friends (76\%), health educators (43.6\%) and poster got the least priority (30.9\%). Conclusion: The study concludes that a substantial proportion of the patients of malocclusion are not aware of the causes and consequence of malocclusion. However, the patients are aware that malocclusion is an aesthetic problem and can be corrected.
\end{abstract}

Key words: Malocclusion, aesthetic problem, treatment seeking behavior.

[BSMMU J 2011; 4(2): 94-98]

\section{Introduction:}

Crowded, irregular and protruding teeth, collectively termed as malocclusion, have been a problem since antiquity, and attempts to cor-rect these disorders go back to at least 1000 BC. ${ }^{1}$ Developmental anomalies of the dentition are frequently observed among the orthodontic patients. Anomalies in tooth number, shape, and position may lead to the disturbances in maxillary and mandibular arch length and occlusion complicating orthodontic treatment planning. Several studies investigated the prevalence of various dental anomalies but only a few

Address for correspondence: Dr. Tanzila Rafique, Department of Orthodontics,Faculty of Dentistry, Bangabandhu Sheikh Mujib Medical University, Dhaka, e-mail: tanzila_rafique@yahoo.com, have been conducted on orthodontic patients. In 1959, Lind $^{2}$ examined1717 Swedish orthodontic patients and found 3.6 percent with supernumerary teeth. Rose ${ }^{3}$ did a survey on the prevalence on 6000 orthodontic patients aged 7 to 14 years and found $4.3 \%$ with at least one congenitally missing tooth. A recent pilot twin study by Kotsomitis et al ${ }^{4}$ on 202 orthodontic patients (101 pairs) reported a prevalence of ectopic eruption of $29.7 \%$ and agenesis $8.4 \%$.

To find the prevalence of malocclusion and treatment need amongst the young Chinese adults, Tang ${ }^{5}$ assessed 108 Chinese male first year dental students in Hong Kong using the Occlusal Index. Of them 41.7\% needed 
orthodontic treatment and $24.1 \%$ needed comprehensive orthodontic treatment to correct major malocclusions. The most commonly occurring feature was crowding (38.9\%) followed by Class II malocclusion and Class III malocclusion (21.3\% and $14.8 \%$ respectively). Ahmed \& Chowdhury ${ }^{6}$ have conducted a survey on 504 orthodontic patients in Bangladesh, where they found delayed shedding of deciduous teeth as the main etiologic factor for class-I malocclusion, dento-alveolar disproportion and skeletal discrepancy as the main factors for class-II malocclusion and loss of upper deciduous and $1^{\text {st }}$ permanent molar were the major factors attributable to Class-III malocclusion. Hossain and associates in a study in Dhaka Dental College and Hospital in 1994 reported Class-I malocclusion as predominant (55\%) followed by Angel's Class-II malocclusion (33.3\%) and Class-III malocclusion (11.7\%).

Orthodontic treatment allows for the improvement of the patient's facial and dental esthetics. It cannot only lead to a beautiful smile but also can make the teeth to occlude better each other. Adequate alignment among the teeth and interdigitation between the arches are important as they may prevent gum recession, trauma to the teeth, cavities, gingivitis, periodontitis and possible loss of teeth in some individuals. But people of our country are not still aware enough of the problems relating to malocclusion. Treatment of malocclusion could reduce the suffering among the people and social embracement if early diagnosis of the specific problem and treatment can be given. This can be ensured by creating population awareness about the causes and consequences of malocclusion. However, no nation-wide survey has yet been conducted to assess the magnitude of malocclusion, its present status and treatment seeking awareness among the patients. The present study is such an initiative to attain this goal.

\section{Methods:}

The present cross-sectional study was carried out in the Department of Orthodontic, Faculty of Dentistry, BSMMU, over a period 24 months from January 2008 to December 2009. All the ethical issues were dealt according to Helsinki Declaration for Research Involving Human Subjects 1964 and informed consent was obtained from them. A total of 110 respondents who were suffering from malocclusion and came for dental treatment were included in the study. Of them 36 respondents were below 18 years (minor) and 7418 or $>18$ years old (adult). In case of minors, one of their parents or attendants was the respondent. Data were collected through face to face interview and physical examination using a structured questionnaire. The demographic variables included in the study were age, sex and education of the respondents. Knowledge of the respondents about malocclusion, its causes, consequences, treatment and prevention were also recorded. Data were processed using software SPSS (Statistical Package for Social Sciences) version I1.5. The test statistics used to analyse the data were descriptive statistics.

\section{Results:}

The mean age of the patients was 21 years and the youngest and the oldest patients were 8 and 32 years old respectively with female to male ratio being roughly 3:2. Graduate or postgraduate level educated patients were predominant (53.6\%) (table I). A substantial proportion of subjects (45\%) in the present study told that they did not know how malocclusion developed. About $24.5 \%$ told it was habitrelated and $30 \%$ told familial. Over $70 \%$ of the respondents were aware about aesthetic problem of malocclusion, 50\% functional problem, 55.5\% social problem and 69.1\% oral problem (table II). Two-third (67\%) told that malocclusion was a treatable condition. Approximately $43 \%$ of the patients identified trauma as a cause of malocclusion, $40 \%$ gingivitis or periodontitis and 35.5\% dental caries (table III). Onethird (32.7\%) of the respondents told that avoiding bad oral habits could prevent malocclusion, $15.5 \%$ told timely treatment of malocclusion, 30\% told prevention of early loss of teeth due to caries, $12.7 \%$ were in favour of the use of a space maintainer in places of premature loss of a deciduous tooth (table IV).

Table-I

Demographic characteristics of the respondents $(n=110)$

\begin{tabular}{lcc}
\hline Demographic characteristics & Frequency & Percentage \\
\hline Age* (years) $^{*}$ & 03 & 2.7 \\
$<10$ & 62 & 18.2 \\
$10-15$ & 56 & 18.2 \\
$15-20$ & 22 & 20.0 \\
$20-25$ & 45 & 40.9 \\
$\geq 25$ & & \\
Sex & 42 & 38.0 \\
Male & 68 & 62.0 \\
Female & & \\
Education & 21 & 19.1 \\
Primary & 10 & 9.1 \\
SSC & 20 & 18.2 \\
HSC & 59 & 53.6 \\
Graduate and Postgraduate & $8-32$ years. \\
Mean \pm SD = 21 \pm 6.6 ; range $=8$ & \\
\hline
\end{tabular}


Table-III

Knowledge of the respondents about malocclusion

$$
(n=110)
$$

\begin{tabular}{|c|c|c|}
\hline \multicolumn{3}{|l|}{ Causes of malocclusion } \\
\hline Habit & 27 & 24.5 \\
\hline Familial & 33 & 30.0 \\
\hline Don't know & 50 & 45.5 \\
\hline \multicolumn{3}{|l|}{ Aware about aesthetic problem } \\
\hline Yes & 78 & 70.9 \\
\hline No & 06 & 5.5 \\
\hline Don’t know & 26 & 23.6 \\
\hline \multicolumn{3}{|l|}{ Aware about functional problem } \\
\hline Yes & 55 & 50.0 \\
\hline No & 37 & 33.7 \\
\hline Don’t know & 18 & 16.3 \\
\hline \multicolumn{3}{|l|}{ Aware about social problem } \\
\hline Yes & 61 & 55.5 \\
\hline No & 41 & 37.2 \\
\hline Don't know & 08 & 7.3 \\
\hline \multicolumn{3}{|l|}{ Aware about oral problem } \\
\hline Yes & 76 & 69.1 \\
\hline No & 09 & 8.2 \\
\hline Don't know & 25 & 22.7 \\
\hline
\end{tabular}

Table-IV

Knowledge about risk factors of malocclusion $(n=110)$

\begin{tabular}{lcc}
\hline Risk factors of malocclusion & Frequency & Total \\
\hline Trauma & 47 & 42.7 \\
Yes & 04 & 3.6 \\
No & 59 & 53.7 \\
Don't know & & \\
Gingivitis/periodontitis & 44 & 40.0 \\
Yes & 05 & 4.5 \\
No & 61 & 55.5 \\
Don't know & & \\
Dental caries & 39 & 35.5 \\
Yes & 04 & 3.6 \\
No & 67 & 60.9 \\
\hline Don't know &
\end{tabular}

Table-V

Knowledge about prevention of malocclusion $(n=110)$

\begin{tabular}{lll}
\hline Knowledge about prevention & Frequency & Total \\
\hline
\end{tabular}

Avoiding bad habit that causes malocclusion

$\begin{array}{lll}\text { Yes } & 36 & 32.7\end{array}$

No $15 \quad 13.6$

Don't know 76

69.1

Timely treatment of malocclusion

Yes

$17 \quad 15.5$

No $\quad 05 \quad 4.5$

Don’t know $\quad 88 \quad 80.0$

Prevention of early loss of teeth due to caries

$\begin{array}{lll}\text { Yes } & 34 & 30.9\end{array}$

Don’t know $\quad 76 \quad 69.1$

Use of space maintainer

$\begin{array}{lll}\text { Yes } & 14 & 12.7\end{array}$

$\begin{array}{lll}\text { No } & 07 & 6.4\end{array}$

Don't know $\quad 89 \quad 80.9$

Table-VI

Opinion of the respondents to educate society for prevention and treatment of malocclusion $\left(n=110^{*}\right)$

\begin{tabular}{lcc}
\hline Respondents’ opinion & Frequency & Total \\
\hline Causative factor & 88 & 80.0 \\
Symptoms & 10 & 94.5 \\
Investigation & 54 & 49.1 \\
Treatment option & 102 & 92.7 \\
Preventive method & 91 & 92.7 \\
\hline
\end{tabular}

Over $90 \%$ of the respondents held the view that symptoms of malocclusion, its prevention and different treatment options should get priority in educating the society about malocclusion. However, $80 \%$ of the respondents told that causative factors should discussed. Investigations were less preferred as an item of education (49\%). Regarding ways of behaviour change communication (BCC), TV got the first priority (94\%) followed by newspaper (92\%), teacher (88\%), school health programme $(84.5 \%)$, friends (76\%), health educators $(43.6 \%)$ and poster got the least priority (30.9\%) (Fig.1). 


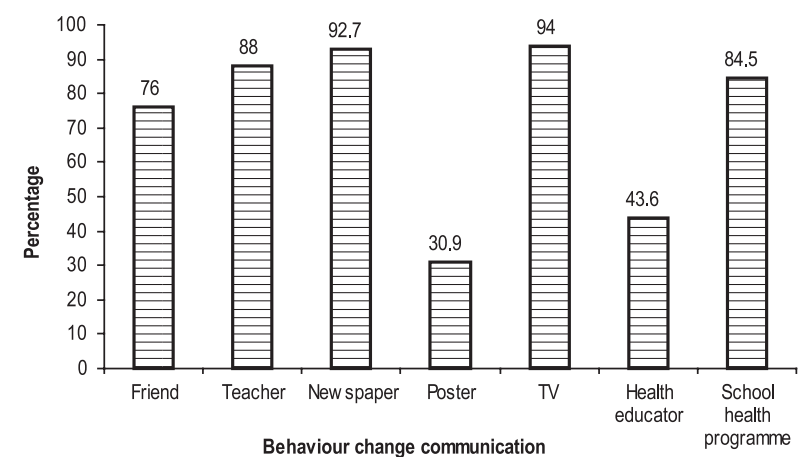

Total will not correspond to $100 \%$, for multiple responses

\section{Discussion:}

With increasing awareness about orthodontic treatment, the demand for the treatment is also increasing rapidly, particularly among the adult population. In addition, increased dental awareness also means that patients are seeking a standard treatment. There are several reasons why one may seek orthodontic treatment. But treatment providers should lay more emphasis on prevention rather that cure. Preventive measures against malocclusion can reduce the amount of money needed for treatment and suffering of the people and social harassment. This can be ensured if we can educate the society and make the population to become aware of the malocclusion and their possible drawbacks, by educating them in different ways.

In the present study, nearly half (45\%) of the subjects told that they did not know how malocclusion developed. About $24.5 \%$ told it was habit-related and $30 \%$ told familial. More than $70 \%$ of the respondents viewed malocclusion as aesthetic problem, $50 \%$ functional problem, $55.5 \%$ social problem and $69.1 \%$ oral problem. A substantial proportion of patients either was not aware of these problems or had misconception that they did not cause any problems. Twothird (67\%) of the respondents told that malocclusion was a treatable condition. Approximately $43 \%$ of the patients identified trauma as a cause of malocclusion, $40 \%$ told gingivitis or periodontitis and $35.5 \%$ told dental caries. Regarding treatment options, $15.5 \%$ respondents told timely treatment of malocclusion, $30 \%$ told prevention of early loss of teeth due to caries, $12.7 \%$ were in favour of use of a space maintainer in places of premature loss of a deciduous tooth. As ways of behaviour change communication (BCC), TV got the first priority followed by newspaper, teacher, school health programme, friends, health educators and poster got the least priority. Over $90 \%$ of the respondents were of the opinion that symptoms, different treatment options available and prevention of malocclusion should get priority in educating the society about malocclusion. However, $80 \%$ of the respondents told that causative factors should be highlighted in educating the society to prevent malocclusion. Investigations were less preferred as an item of education (49\%). Thus it is evident, that a majority of the patients either was not aware of these problems or had misconception about the causes of these problems.

The social and psychological influence of dental and facial appearance have been reported to have an important influence on people's perception of friendliness, social class, popularity and intelligence of an individual ${ }^{7}$, The most salient feature in one study was the protrusion of the upper teeth ${ }^{8}$, although background facial attractiveness appears to be more influential than the individual's dental condition. The importance of dental appearance to an individual does not seem to be influenced by social background or education. The appearance of the teeth seems to rank as a high priority for both males and females ${ }^{9}$.

There is also an association between an individual's concepts of body image and low self-esteem. In relation to malocclusion, this tends to persist beyond childhood into adulthood ${ }^{10}$. Ironically, it appears that milder deviations in facial form, such as 'buck teeth', that tend to evoke ridicule and teasing, can be more damaging psychologically than the more severe deformities that tend to elicit strong emotional reactions such as pity or revulsion. A further problem with facial and dental deformity is that in social interaction it is invariably impossible to hide or disguise it, because in normal interaction the eyes attend the face ${ }^{11}$. In schoolchildren, deviations of dental appearance have been found to be a target for teasing. The greater the deviation of the dental appearance, the greater the implication to the child and comments about teeth appeared to be more hurtful than those about other features ${ }^{8}$. A group of patients with a Class II division 1 malocclusion who underwent early treatment to correct their 'goofy teeth' revealed that the patients did not generally present for treatment with low self-concept ${ }^{12}$. In another study on school children undergoing orthodontic treatment, fixed appliances were found to attract more negative comments from both patients and parents than removable appliances, and parents had significantly more negative perceptions of both appliance types than the patient group ${ }^{13}$. The benefits of orthodontics for an improvement in body image have been documented for an adult population ${ }^{14}$ but in children, although there is usually an improvement in self-evaluation of dental-facial attractiveness with orthodontic treatment ${ }^{15}$ 
it does not appear to improve overall body image or selfesteem $^{16,17}$.

In another study, however, a group of patients followed from their adolescence into adulthood, who had not received orthodontic treatment, showed that awareness of malocclusion increases with age ${ }^{10}$. It has also been shown that students with malocclusion who had not received orthodontic treatment have a lower achievement motivation than students who have received treatment ${ }^{18}$. This may indicate the role of status-seeking as a motive for orthodontic treatment, which is affected by socioeconomic factors. A child's psychological profile may influence treatment demand, as those with high self-esteem initially appear more likely to seek improvement of their teeth $^{17}$.

A study on Index Orthdontic Treatment Need (IOTN) was carried out in Dhaka Dental College \& Hospital in 1997 by Akhter ${ }^{19}$ to assess the treatment need of the patients of malocclusion. The present study, however, differs in that the study tried to explore the patients' perception about different aspects of malocclusion. Although the study revealed a substantial proportion of our population was unaware of malocclusion and its treatment, the sample was not representative of the whole population (hospitalbased) to generalize the findings of the study.

\section{Conclusion:}

From the above discussion, it is suggested that treatment of malocclusion should be instituted as early as possible for improvement of facial appearance and body image. But in a society like ours where most people are not aware of its social consequences, educational intervention should be considered to make people aware of the adverse consequences of malocclusion and this should be launched as priority basis. A large-scale community-based study is, therefore, recommended to assess people's perception about malocclusion and based on which the treatment strategy could to be planned.

\section{References:}

1. Proffil WR. Fields HW. Ackerman JL. Sinclair PM. Thomas PM. Tulloch GIF. Contemporary orthodontics. 2nd ed. Si Louis: Mosby Year Book. 1993.

2. Lind V. Medfodda antalsvariationer i permanenta dentitionen.Odont Rev 1959;10:176-89.
3. Rose JS. A survey of congenitally missing teeth, excluding third molars, in 6000 orthodontic patients. Dent Pract (Bristol) 1996;17:107-143.

4. Kotsomitis N, Dunne MP, Freer TJ. A genetic aetiology for some common dental anomalies: a pilot twin study. Aust Orthod J 1996;14:172-8.

5. Tang EL. The prevalence of malocclusion amongst Hong Kong male dental students. Br J Orthodon 1995;21:57-63.

6. Ahmed N \& Chowdhury K. Prevalence of malocclusion and its etiological factors. J Oral Health 1996;2(2):12.

7. Secord PF, Backman CW. Malocclusion and psychological factors. J Am Dent Assoc 1959; 59: 931-8.

8. Shaw WC, Rees G, Dawe M, Charles CR. The influence of dentofacial appearance on the social attractiveness of young adults. Am J Orthod 1985; 87:21-6.

9. Lerner RM, Karabenick SA, Stuart JL. Relations among physical attractiveness, body attitudes, and selfconcept in male and female college students. J Psychol 1973;85:119-29.

10. Helm S, Kreilborg S, Solow B. Psychosocial implications of malocclusion: a 15-year follow-up study in 30-year-old Danes. Am J Orthod 1985;87:110-8.

11. Macgregor FC. Social and psychological implications of dentofacial disfigurement. Angle Orthod 1970; 40:231-3.

12. Dann C, Phillips C, Broder HL, Tulloch JFC. Selfconcept, Class II malocclusion, and early treatment. Angle Orthod 1995;65:411-6.

13. Prove SA, Freer TJ, Taverne AA. Perceptions of orthodontic appliances among grade seven students and their parents. Aust Orthod J 1997;15:30-7.

14. Varela M, García-Camba JE. Impact of orthodontics on the psychologic profile of adult patients: a prospective study. Am J Orthod Dentofacial Orthop 1995;108:142-8.

15. Albino JEN, Lawrence SD, Tedesco LA. Psychological and social effects of orthodontic treatment. J Behav Med 1994;17:81-98.

16. Klima RJ, Wittemann JK, McIver JE. Body image, selfconcept, and the orthodontic patient. Am J Orthod 1979;75:507-16.

17. Birkeland K, Boe OE, Wisth PJ. Relationship between occlusion and satisfaction with dental appearance in orthodontically treated and untreated groups. A longitudinal study. Eur J Orthod 2000;22:509-18.

18. Hilzenrath SS, Baldwin DC. Achievement motivation - a factor in seeking orthodontic treatment. IADR 1970;49:Abstract 433.

19. Akhter F. Evaluation of different malocclusion and probable treatment based on IOTN attending at Dhaka Dental College \& Hospital. Dissertation, 2007. 